\title{
The role of temporary mechanical circulatory support in an effective surgical treatment of a left ventricular aneurysm and a ventricular septal defect in a patient after anterior wall myocardial infarction
}

\author{
Krzysztof Wróbel', Karolina Żbikowska1,4, Ryszard Wojdyga', Ewelina Pirsztuk³, Marcin Zygier', Katarzyna Kurnicka²
}

'Department of Cardiac Surgery, Medicover Hospital, Warszawa, Poland

${ }^{2}$ Department of Internal Medicine and Cardiology, Medical University of Warsaw, Warszawa, Poland

${ }^{3}$ Department of Anesthesia and Intensive Care, Medicover Hospital, Warszawa, Poland

${ }^{4}$ Department of Cardiac Surgery, Medical University of Warsaw, Warszawa, Poland

Correspondence to: Karolina Żbikowska, MD, Department of Cardiac Surgery, Medical University of Warsaw,

Stefana Banacha 1A,

02-097 Warszawa, Poland, phone: +48 225992161 .

e-mail:

karolina_zbikowska@wp.pl

Copyright by the

Author(s), 2021

Kardiol Pol. 2021;

79 (6): 718-719;

DOI: 10.33963/KP.15968

Received:

February 4, 2021

Revision accepted: April 13, 2021

Published online: April 20, 2021
Referring to the discussion on effective methods of treatment for patients with a post-infarction left ventricular aneurysm and a ventricular septal defect (VSD) [1], we present the case of a 57-year-old man with hypertension, chronic renal failure, and Crohn's disease who was admitted to the cardiac surgery department due to cardiogenic shock in the course of acute ST-segment elevation myocardial infarction of the anterior wall, complicated by rupture of the interventricular septum (IVS) and large left ventricular aneurysm within the apex. In the patient's history, an acute cardiac pain occurred six days before hospitalization in the department of cardiology. Coronary angiography revealed the left anterior descending artery with a very narrow 8 th segment and a significantly stenosed marginal artery treated with one drug-eluting stent implantation. Transthoracic echocardiography showed akinesis with the thinning of apical segments of the left ventricle (LV) walls and the mid-anterior part of IVS (Figure $1 \mathrm{~A}$ ), dyskinesis of the apex and hyperkinesis of hypertrophied basal segments. LV ejection fraction was approximately $36 \%$. In the apical segment of the IVS a $5 \mathrm{~mm}$ VSD with the leftright shunt was exposed (Figure 1B). The patient was qualified for a delayed surgical treatment after day 12 with femoral veno-arterial extracorporeal membrane oxygenation (VA-ECMO), instituted 8 hours after admission, as well as CRRT (renal failure, metabolic acidosis). He was extubated next morning. His hemodynamic and metabolic status improved in the next few days. On day 19 after the first symptoms of myocardial infarction, in a stable patient's condition, LV repair and VSD closure were performed using 2 goretex patches (Figure 1C). VA-ECMO was continued for the next 4 days. In the early postoperative phase, the patient required bedside dialysis and inotropic support. On day 3, levosimendan was administered. Two weeks after the surgery, the patient was discharged home in a good general condition. Almost 3 months after the surgery, a follow-up transthoracic echocardiography revealed no shunt between ventricles (Figure 1D) and showed an improved LV shape (Figure 1E-F). The LV end-diastolic volume was $180 \mathrm{ml}$, SV $60 \mathrm{ml}$ and $\mathrm{EF} 35 \%$.

VSD of the apical IVS segment develops typically in the course of a transmural anterior infarction, frequently in the absence of reperfusion therapy or delayed reperfusion $[2,3]$. Surgery is an effective method of treatment, but with a high risk of complications, often due to the patient's hemodynamic instability and post-infarction fragility of tissues associated with increased activity of metalloproteinases and myocardial remodeling. Reports of recent years have drawn attention to the role of a delayed surgical treatment with the use of mechanical circulatory support devices [4]. Temporary VA-ECMO support may significantly contribute to the achievement of good therapeutic results by stabilizing the patient, maintaining adequate tissue oxygenation [4], obtaining time for myocardial remodeling, and elimination of the effect of antiplatelet therapy and further therapeutic decisions [5]. In patients 


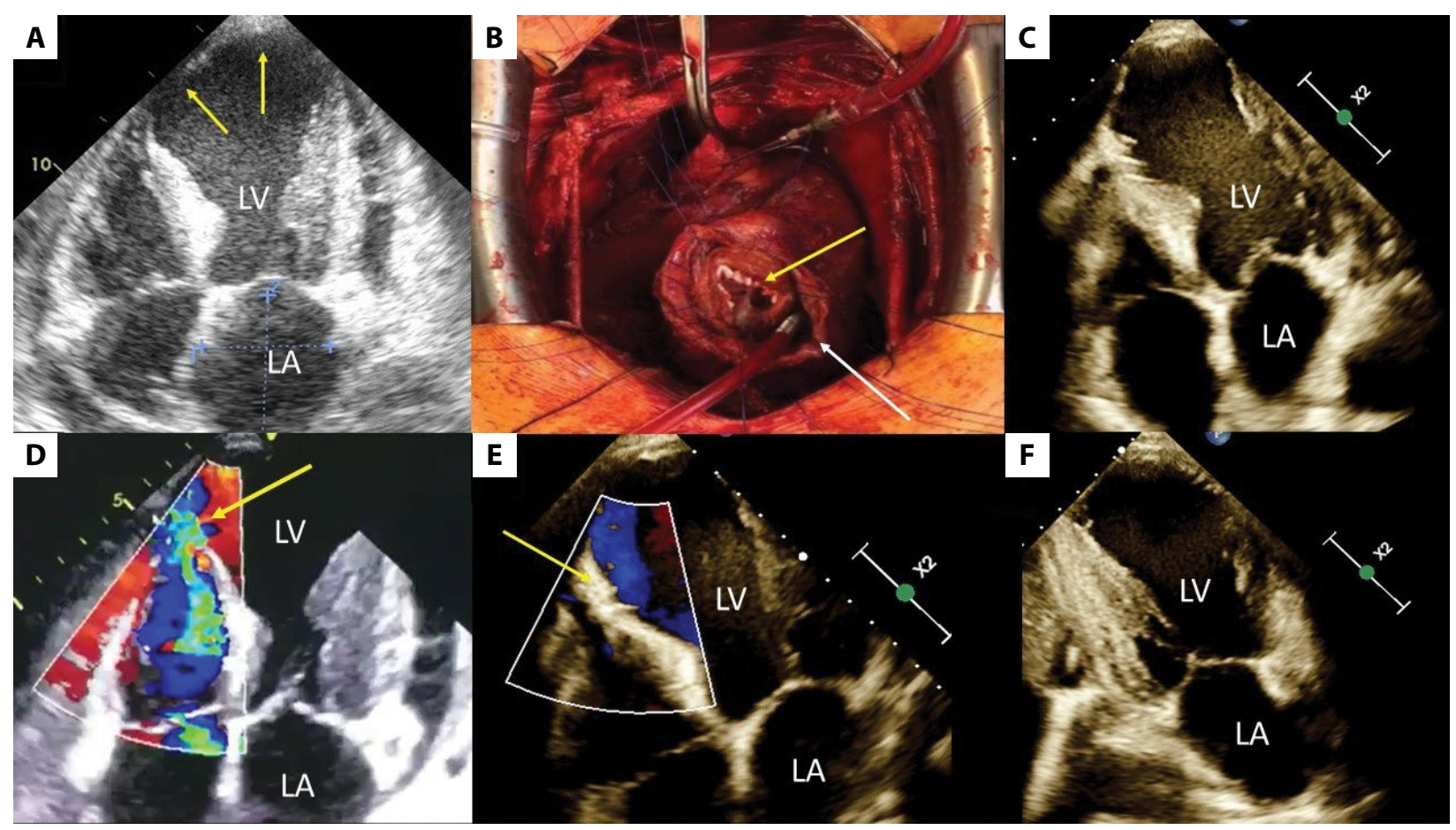

Figure 1. A. A large apical left ventricular aneurysm (arrows); two-dimensional transesophageal echocardiography, a four-chamber view. B. Ventricular septal defect in the apical segment of the interventricular septum (arrow); two-dimensional transesophageal echocardiography, color Doppler, a four-chamber view. C. Left ventricle aneurysm opened (white arrow). Ventricular septal defect with single pledgeted sutures (yellow arrow); an intraoperative view. D. Apical segment of the interventricular septum without the shunt between ventricles; ventricular septal defect patch (arrow); two-dimensional transesophageal echocardiography, color Doppler, a four-chamber view. E. An improved shape and volume of the left ventricle on follow-up echocardiography in a four chamber view. F. Two-chamber view.

Abbreviations: LA, left atrium; LV, left ventricle

without cardiogenic shock ECMO should be considered individually in order to unload the ventricles and prevent hemodynamic deterioration (large VSDs and impending deterioration, severe RV infarction, progressive dilatation of cardiac chambers).

\section{Article information}

Conflict of interest: None declared.

Open access: This article is available in open access under Creative Common Attribution-Non-Commercial-No Derivatives 4.0 International (CC BY-NC-ND 4.0) license, allowing to download articles and share them with others as long as they credit the authors and the publisher, but without permission to change them in any way or use them commercially. For commercial use, please contact the journal office at kardiologiapolska@ptkardio.pl.

How to cite: Wróbel K, Żbikowska K, Wojdyga R, et al. The role of temporary mechanical circulatory support in an effective surgical treatment of a left ventricular aneurysm and a ventricular septal defect in a patient after anterior wall myocardial infarction. Kardiol Pol. 2021; 79(6): 718-719, doi: 10.33963/KP.15968.

\section{REFERENCES}

1. Bednarek A, Wieczorek J, Elżbieciak $M$, et al. Treatment strategies for a giant left ventricular aneurysm and developing ventricular septal defect in a patient after anterior wall myocardial infarction. Kardiol Pol. 2020; 78(1): 86-88, doi: 10.33963/KP.15076, indexed in Pubmed: 31782751.

2. Jones BM, Kapadia SR, Smedira NG, et al. Ventricular septal rupture complicating acute myocardial infarction: a contemporary review. Eur Heart J. 2014; 35(31): 2060-2068, doi: 10.1093/eurheartj/ehu248, indexed in Pubmed: 24970335.

3. Honda S, Asaumi Y, Yamane T, et al. Trends in the clinical and pathological characteristics of cardiac rupture in patients with acute myocardial infarction over 35 years. J Am Heart Assoc. 2014; 3(5): e000984, doi: 10.1161/JAHA.114.000984, indexed in Pubmed: 25332178.

4. Morimura $\mathrm{H}$, Tabata M. Delayed surgery after mechanical circulatory support for ventricular septal rupture with cardiogenic shock. Interact Cardiovasc Thorac Surg. 2020;31(6):868-873, doi: 10.1093/icvts/ivaa185, indexed in Pubmed: 33118011.

5. Goyal A, Menon V. Contemporary management of post-Ml ventricular septal rupture. J Am Coll Cardiol. 2018. 